\title{
Total Pericardiectomy via Modified Left Anterolateral Thoracotomy without Cardiopulmonary Bypass (UKC's Modification): A Video Presentation
}

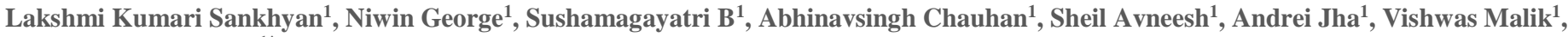 \\ Ujjwal K. Chowdhury ${ }^{*}$, \\ ${ }^{1}$ Cardiothoracic Sciences Centre All India Institute of Medical Sciences, New Delhi
}

*Corresponding Author: Ujjwal Kumar Chowdhury, Department of Cardiothoracic and Vascular Surgery All India Institute of Medical Sciencess

Received Date: November 18, 2020; Accepted Date: December 12, 2020; Published Date: December 18, 2020

Citation: Lakshmi K. Sankhyan., Niwin George, Sushamagayatri B, Abhinavsingh Chauhan, Sheil Avneesh, Andrei Jha, Vishwas Malik, Ujjwal K. Chowdhury, (2020) Total Pericardiectomy via Modified Left Anterolateral Thoracotomy without Cardiopulmonary Bypass (UKC's Modification): A Video Presentation. J. Clinical Cardiology and Cardiovascular Interventions, 3(13); Doi:10.31579/2641-0419/108

Copyright: (C) 2020 Ujjwal Kumar Chowdhury, This is an open-access article distributed under the terms of the Creative Commons Attribution License, which permits unrestricted use, distribution, and reproduction in any medium, provided the original author and source are credited.

\begin{abstract}
:
We report one male patient aged 28-years undergoing total pericardiectomy for chronic calcific pericarditis with an uneventful postoperative course. The step-by-step surgical procedure of total pericardiectomy via modified left anterolateral thoracotomy without utilizing cardiopulmonary bypass has been detailed.

Key words: chronic constrictive pericarditis; calcific constrictive pericarditis; left anterolateral thoracotomy; low cardiac output syndrome
\end{abstract}

\section{Introduction:}

Despite the experience spanning over 100 years, there is no fool-proof formula in the published literature to decide the optimal approach for a given patient. The literature is rife with descriptions of pericardiectomy by either left anterolateral thoracotomy or median sternotomy. Despite the effectiveness of surgery, there are disparate opinions regarding the role of corticosteroids in treating tuberculous pericarditis, timing of operation, surgical approach, and extent of decortication and requirement of cardiopulmonary bypass.[1-6] The efficacy of pericardiocentesis in preventing chronic constrictive pericarditis in pericardial effusion (serous/or hemorrhagic) has been inadequately investigated. ${ }^{6}$ The terms "total", "radical", "complete", "extensive", "adequate", "subtotal", "neartotal" and partial pericardiectomy have been variably used to describe the procedure, often without precise definition of the limits of pericardial resection. [1-6]

Published reports attest to the unpredictable and variable pattern of chronic constrictive pericarditis and lend support to radical decortication. In 2020, for the sake of uniformity with other studies we redefined "total pericardiectomy" when a patient had wide pericardial excision over the anterolateral, the diaphragmatic surfaces of both ventricles, the pericardium posterior to the phrenic nerve with intact phrenic pedicles and over the great vessels including the intrapericardial vena cava-right atrial junctions. ${ }^{7}$ The term "partial pericardiectomy" is reserved for anything less than total pericardiectomy. " Radical pericardiectomy" will be more defined in terms of relation to oncological situations where draining lymphatics/ lymph nodes will be removed as well. In addition, "radical pericardiectomy" is something that is never possible as it requires removal of all three layers of pericardium, which are "fibrous" and "serous" with two components: "parietal and visceral epicardium" and that is not possible in real life. [7]

The importance of unrecognized constricting epicardial (visceral pericardial) peel was described by Harrington in 1944 and successful pericardiectomy requires decortication of the ventricular epicardium and relief of all constricting layers. ${ }^{2}$ In a study, the normalization of pressure volume loop was used as an indicator of operative success of pericardiectomy. [8]

We concur with the observation of other investigators that routine use of cardiopulmonary bypass to achieve total pericardiectomy in unnecessary and should be employed in special circumstances, namely (1) inadvertent damage to a cardiac chamber, (2) cardiac operation, or previous partial pericardiectomy, (3) presence of calcific pericardial "cocoon" encompassing all cardiac chambers, (4) pericardiectomy following mediastinal irradiation and (5) coexistent cardiac lesion. ${ }^{9-15}$ Additionally, cardiopulmonary bypass allows control of fluid shifts, ultrafiltrate some of this fluid off, thus prevents cardiac distension.

In 2005, we compared two surgical approaches for the treatment of chronic constrictive pericarditis i.e., median sternotomy and conventional left anterolateral thoracotomy in 395 patients. The surgical approach was 
primarily based on surgeon's preference and remained uniform. ${ }^{9}$ However, the median sternotomy approach was preferred in the following conditions: (i) annular chronic constrictive pericarditis, (ii) calcific pericardial patch compressing the right atrium and right ventricular outflow tract, (iii) presence of a gradient between the superior or inferior venae cavae and right atrium of $2 \mathrm{mmHg}$ or greater, (iv) extracardiac intrapericardial mass, (v) previous open heart surgery, (vi) circumferential 'cocoon' calcification of the pericardium, and (vii) recurrent chronic constrictive pericarditis after partial pericardiectomy. [9]

Despite total pericardiectomy, the operative mortality rate was $7.6 \%$ in our series and 6-19\% in several large series published after 1985 and the reported incidence of low cardiac output syndrome ranges from 50\%$69 \% \cdot[5,9-11,13-17]$ To decrease the hospital mortality rates of $7.6 \%$ and postoperative low-output syndrome of $69 \%$, the author proceeded to perform several technical modifications of the conventional left anterolateral thoracotomy approach to achieve further radical excision of the pericardium posterior to the phrenic nerve and diaphragmatic pericardium.[13]

We published our preliminary observations on total pericardiectomy via modified left anterolateral thoracotomy and detailed the surgical techniques in Journal of Operative Techniques of Thoracic Cardiovascular Surgery in 2008.[13]

We report here-in a 28 -years-old male patient who underwent total pericardiectomy for calcific constrictive pericarditis via left anterolateral thoracotomy without cardiopulmonary bypass. Postoperatively, his mean right atrial pressure was $24 \mathrm{mmHg}$ with massive ascites, bilateral pleural effusion, left ventricular ejection fraction of 0.40, and in New York Heart Association functional class IV. The mitral and tricuspid valves are normal.

\section{Surgical Techniques}

\section{Ujijwal-CCP-LALT-Video (JCCI).mp4}

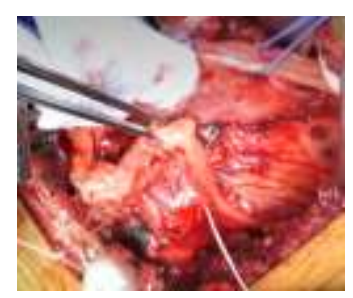

\section{Positioning of the patient}

The patient was prepared for left anterolateral thoracotomy with the patient tilted slightly to the right. Both the groins were positioned and draped for emergent exposure of the femoral vessels and institution of cardiopulmonary bypass if required.

The chest was entered via left $5^{\text {th }}$ intercostal space. The left internal thoracic artery was transfixed and divided. The intercostal muscles were divided posteriorly almost till the angle of the ribs to facilitate opening of the retractor blade without causing any rib fractures. A deep bladed retractor was used to facilitate undercutting of the intercostal muscles. We do not transect the sternum to gain exposure to right ventricle and right atrium across midline but employ several maneuvers as described below to facilitate exposure to the right-sided cardiac chambers with certainty and safety.

Removal of the excessive fat overlying the left ventricular apex and left phrenic nerve; subtotal thymectomy

A large wet abdominal sponge was placed over the left lung and retracted posteriorly to facilitate exposure. It is important to identify the left phrenic neurovascular pedicle after removing the large amount of fat which usually overlies left ventricular apex in close proximity to the left phrenic nerve.

The thymus was routinely dissected off the pericardium to facilitate exposure of the pericardium over the ascending aorta and pulmonary artery. The thymus was excised subtotally; transfixing the superior pole of the thymic gland.

Development of a new dissection plane between the sternum and the anterior surface of the pericardium

The posterior table of the sternum was retracted using a right angled deep blade retractor and a new dissection plane was developed using cautery between the sternum and the anterior surface of the pericardium.

\section{Extension of the dissection plane beyond the midsternum to the right} phrenic pedicle

Three silk sutures were employed over the anterior portion of the pericardium to facilitate traction thereby extending the newly developed dissection plane beyond the midsternum to the right phrenic pedicle.

Development of a new cleavage plane between the diaphragmatic pericardium and diaphragm

Using cautery dissection, a new cleavage plane was partially developed between the diaphragmatic pericardium and diaphragm.

Mobilisation and isolation of the left phrenic pedicle.

After exposing the pericardium, two full-length parallel incisions were made using a cautery with low voltage (around $8-10 \mathrm{mV}$ ) $0.5 \mathrm{~cm}$ anterior and posterior to the left phrenic neurovascular pedicle and extended until the level of the pulmonary artery superiorly and diaphragm inferiorly. Multiple silk stay sutures were placed on the incised pericardial edges anteriorly and posteriorly to achieve exposure and the left phrenic pedicle was thereafter isolated using two elastomer vessel loops.

Dissection of the pericardium posterior to the left phrenic nerve and division of the posterior pericardium in two halves

Posteriorly, the pericardium was gently dissected and raised from posterolateral surface of the left ventricle and left atrial appendage. The midportion of the posterior pericardial flap was subsequently divided in the centre in two halves to facilitate adequate mobilization until the levels of left-sided pulmonary veins and excised. 
Dissection of the pericardium anterior to the phrenic nerve and division of the anterior pericardium in two halves

Using cautery at 8 to $10 \mathrm{mv}$, the anterior pericardial flap was thereafter raised from the right ventricle and pulmonary artery. Four to five silk stay sutures on the anterior pericardial edge is extremely helpful during the process of dissection.

The anterior pericardial flap (APF) was subsequently divided in two halves in the centre to minimize intermittent cardiac compression and unstable hemodynamics. While raising the anterior pericardial flap, the surgeon should be more cautious to avoid injury to the dilated and thinned right atrium and inferior cavo-atrial junction.

Anteriorly, the pericardium was dissected till about $0.5 \mathrm{~cm}$ anterior to the right phrenic nerve. The anterior flap was thereafter excised till the level of the ascending aorta superiorly and inferior vena cava-right atrial junction inferiorly.

Development of a new cleavage plane between the diaphragmatic pericardium and diaphragm.

Inferiorly, a new cleavage plane was developed between the diaphragm and thickened pericardium all along its length. We encountered a loculated pus cavity in the area of diaphragmatic and anterior pericardium. The pus cavity was opened and the putty like materials were removed to facilitate exposure. Three to four silk stay sutures were placed on the edges of the diaphragmatic pericardium, dividing into two halves. A dissection plane was developed between the pericardium and diaphragmatic surface of the right ventricle including the left ventricle. The apex was completely freed from the pericardial adhesions. After the cardiac chambers were freed off the underlying adhesions, the entire width of diaphragmatic pericardium was excised in toto taking special precaution near the inferior cavo-atrial junction.

All constricting epicardial layers were peeled off the cardiac chambers and great vessels taking care not to injure the underlying structures including the coronary arteries and veins.

Calcific plaques, bars, and circumferential patches of calcified pericardium were divided using a thick hemostat and a bone cutter, and was removed avoiding injury to the phrenic nerves and the underlying vascular structures.

\section{Results}

Postoperatively, he had stable hemodynamics on dopamine $10 \mu \mathrm{g} / \mathrm{kg} / \mathrm{min}$, dobutamine $10 \mu \mathrm{g} / \mathrm{kg} / \mathrm{min}$ and noradrenaline $0.01 \mu \mathrm{g} / \mathrm{kg} / \mathrm{min}$. His mean postoperative right atrial pressure was $6 \mathrm{mmHg}$ and had an uneventful postoperative course. He was discharged on $10^{\text {th }}$ postoperative day. At 36 months of follow-up, he was doing well and in New York Heart Association functional class I.

\section{Conclusions}

We conclude that total pericardiectomy via modified left anterolateral thoracotomy is an expedient, safe and effective technique in select instances of calcific chronic constrictive pericarditis. Knowledge of this approach should contribute to the armamentarium of cardiac surgeon faced with calcific chronic constrictive pericarditis.

\section{Declaration of conflicting interests}

The author(s) declared no potential conflicts of interest with respect to the research, authorship and/or publication of the article.

\section{Funding}

The authors received no financial support for the research, authorship and/or publication of this article.

\section{References}

1. Rehn and Sauerbruch. Chronic constrictive pericarditis (Pick's disease) treated by pericardial resection. Lancet. 1935;2:539597.

2. Harrington SW. Chronic constrictive pericarditis. Partial pericardiectomy and epicardiolysis in twenty-four cases. Ann Surg. 1944;120(4):468-485.

3. Copeland JG, Stinson EB, Griepp RB, Shumway NE. Surgical treatment of chronic constrictive pericarditis using cardiopulmonary bypass. J Thorac Cardiovasc Surg. 1975;69(2):236-238.

4. Bozbuga N, Erentug V, Eren E, Erdogan HB, Kirali K, Antalet A, et al. Pericardiectomy for chronic constrictive tuberculous pericarditis. Tex Heart Inst J. 2003;30(3):180-185.

5. Clare GC, Troughton RW. Management of constrictive pericarditis in the 21st century. Curr Treat Options Cardiovasc Med. 2007;9(6):436-442.

6. Merce J, Sagrista-Sauleda J, Permanyer-Miralda G, Soler-Soler J. Should pericardial drainage be performed routinely in patients who have a large pericardial effusion without tamponade? Am J Med. 1998;105(2):106-109.

7. Chowdhury UK, George N, Singh S, Sankhyan LK, Sengupta $\mathrm{S}$, et al. Total Pericardiectomy via modified left anterolateral thoracotomy without cardiopulmonary bypass running head. Accepted for publication in Ann Thorac Surg, 2020 (In Press).s

8. Kloster FR, Crislip RL, Bristow JD, Herr RH, Ritzmann LW, Griswold HE. Hemodynamic studies following pericardiectomy for constrictive pericarditis. Circulation. 1965;32:415-424.

9. Chowdhury UK, Subramaniam GK, Kumar AS, Airan B, Singh $\mathrm{R}$, Talwar S, et al. Pericardiectomy for constrictive pericarditis: A clinical, echocardiographic, and hemodynamic evaluation of two surgical techniques. Ann Thorac Surg. 2006;81(2):522529.

10. Ling LH, Oh JK, Schaff HV, Danielson GK, Mahoney DW, Seward JB, et al. Constrictive pericarditis in the modern era: Evolving clinical spectrum and impact on outcome after pericardiectomy. Circulation. 1999;100(13):1380- 1386.

11. McCaughan BC, Schoff HV, Piehler JM, Danielson GK, Otszulak TA, Puga FJ, et al. Early and late results of 
pericardiectomy for constrictive pericarditis. J Thorac Cardiovasc Surg. 1985;89(3):340-350.

12. Copeland JG, Stinson EB, Griepp RB, Shumway NE. Surgical treatment of chronic constrictive pericarditis using cardiopulmonary bypass. J Thorac Cardiovasc Surg. 1975;69(2):236-238.

13. Chowdhury UK, Seth S, Reddy SM. Pericardiectomy for chronic constrictive pericarditis. J Operative Tech Thorac Cardiovasc Surg. 2008;13(1):14-25.

14. Chowdhury UK, Narag R, Malhotra P, Choudhury M, Choudhury A, Singh SP. Indications, timing and techniques of radical pericardiectomy via modified left anterolateral thoracotomy (UKC's modification) and total pericardiectomy via median sternotomy (Holman and Willett) without cardiopulmonary bypass. J Prac Cardiovasc Sci. 2016;2(1):1727.

15. Culliford AT, Lipton M, Spencer FC. Operation for chronic constrictive pericarditis: Do the surgical approach and degree of pericardial resection influence the outcome significantly? Ann Thorac Surg 1980;29:146-152.

16. Saidi F, Scannell JG. Re-operation for constrictive pericarditis after a long period of clinical remission. J Thorac Cardiovasc Surg 1962;43:615-621.

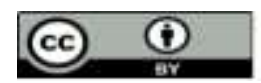

This work is licensed under Creative Commons Attribution 4.0 License

To Submit Your Article Click Here: Submit Article

DOI: $10.31579 / 2641-0419 / 108$
Ready to submit your research? Choose Auctores and benefit from:

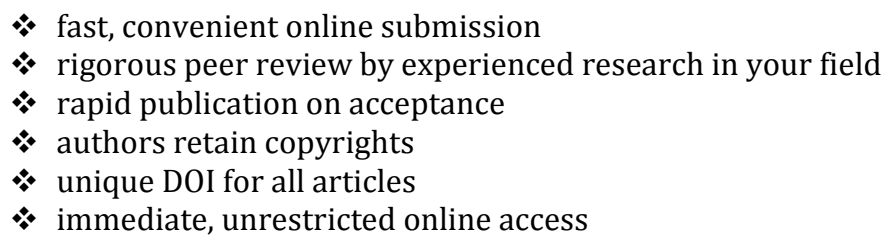

At Auctores, research is always in progress.

Learn more www.auctoresonline.org/journals/clinical-cardiology-andcardiovascular-interventions 